\title{
LKB1 inhibits the proliferation of gastric cancer cells by suppressing the nuclear translocation of Yap and $\beta$-catenin
}

\author{
LIAN-GANG MA $^{1 *}$, SHI-BO BIAN ${ }^{1 *}$, JIAN-XIN CUI $^{1}$, HONG-QING XI $^{1}$, KE-CHENG ZHANG $^{1}$, \\ HONG-ZHEN QIN ${ }^{1}$, XIAO-MING ZHU ${ }^{2}$ and LIN CHEN ${ }^{1}$ \\ ${ }^{1}$ Department of General Surgery, Chinese People's Liberation Army General Hospital, Beijing 100853; \\ ${ }^{2}$ Institute of Basic Medical Sciences, Chinese People's Liberation Army Academy \\ of Military Medical Sciences, Beijing 100850, P.R. China
}

Received August 15, 2015; Accepted February 1, 2016

DOI: $10.3892 / \mathrm{ijmm} .2016 .2494$

\begin{abstract}
Liver kinase B1 (LKB1) is known to suppress the proliferation, energy metabolism and mesenchymal transition of various cancer cells, and is involved in the regulation of Hippo-Yes-associated protein (Yap) and the Wnt/ $\beta$-catenin signaling pathways. However, the role of LKB1 in gastric cancer (GC) was not fully understood. Thus, in the present study, we studied LKB1 and found that protein expression $(0.37 \pm 0.061$ vs. $0.59 \pm 0.108, \mathrm{P}=0.006)$ and the protein ratio of p-Yap/Yap $(0.179 \pm 0.085$ vs. $0.8 \pm 0.126, \mathrm{P}=0.001)$ were reduced in 54 gastric adenocarcinoma (GAC) tissues compared with the matched adjacent non-cancerous tissues, using western blotting and RT-qPCR assays. LKB1 expression was also observed decreased in 109 GAC tissues compared with 54 adjacent non-cancerous tissues $\left(\chi^{2}=4.678, \mathrm{P}=0.0306\right)$, and negatively correlated with the nuclear expression of Yap $(r=-0.6997)$ and $\beta$-catenin ( $\mathrm{r}=-0.3510)$, using immunohistochemical analysis. In GC patients, LKB1 expression was negatively associated with tumor size, tumor infiltration, lymph node metastasis and the TNM stage. LKB1 expression was determined to be positively correlated with longer overall survival of GC patients using Kaplan-Meier analysis $(\mathrm{P}=0.001)$. Subsequently, LKB1 expression in human GAC AGS cells was enhanced with a full-length LKB1 transfection. In vitro and in vivo proliferation was inhibited in LKB1-overexpressing GC cells compared with the control cells. Yap and $\beta$-catenin expression were assessed by western blotting and RT-qPCR, and were found to be increased in the cytoplasm but decreased in the nucleus in LKB1-overexpressing GC cells compared with the control cells. The increase in cytoplasmic $\beta$-catenin was
\end{abstract}

Correspondence to: Professor Lin Chen, Department of General Surgery, Chinese People's Liberation Army General Hospital, 28 Fuxing Road, Beijing 100853, P.R. China

E-mail: chenlinbj@sina.com

${ }^{*}$ Contributed equally

Key words: liver kinase B1, Yap, $\beta$-catenin, nuclear translocation, gastric cancer reversed by the silencing of LKB1 or Yap with shRNAs in LKB1-overexpressing GC cells. Moreover, Yap and $\beta$-catenin mRNA were barely altered by LKB1 overexpression. Thus, we concluded that LKB1 expression was reduced in GAC tissues but that it correlated positively with better prognosis for GC patients. LKB1 inhibits the proliferation of GC cells by suppressing the nuclear translocation of Yap and $\beta$-catenin.

\section{Introduction}

Germline mutations in the tumor suppressor liver kinase B1 (LKB1), a serine/threonine kinase, lead to Peutz-Jeghers syndrome, which predisposes patients to gastrointestinal tumors (1). The loss of LKB1 owing to mutations is an important cause of tumorigenesis, and the rate of LKB1 sporadic mutation is high in many types of malignant tumors, including non-small cell lung cancer (90\%) (2), cervical cancer (20\%) (3), hepatic cancer (22\%) (4) and pancreatic adenocarcinoma (26\%) (5). By contrast, high-throughput mutation profiling has shown that sporadic LKB1 mutations are rare in metastatic (3.4\%) (6), advanced (2.1\%) (7), and early (2/15) (8) gastric cancer (GC). Therefore, the aberrant LKB1-induced dysregulation of signaling pathways, rather than sporadic mutations in LKB1, is associated with GC initiation and progression.

As a critical regulator of a variety of signaling pathways (9), LKB1 phosphorylates and thus activates adenosine monophosphate (AMP)-activated protein kinase (AMPK). AMPK suppresses the mammalian target of rapamycin (mTOR), and thereby inhibits proliferation, polarity and energy metabolism of cancer cells (10-13). LKBI is also an essential tumor suppressor in the Wnt/ $\beta$-catenin (14), Hedgehog (15) and Hippo (10) signaling pathways, where it blocks the growth, migration, and epithelial-mesenchymal transition of cancer cells.

In the Hippo signaling pathway, LKB1 phosphorylates the Yes-associated protein (Yap) indirectly, by phosphorylating cytoplasmic LATS1/2, which is a pivotal mediator of Hippo signaling. Phosphorylated (p-)Yap is sequestrated outside the nucleus; however, in the absence of phosphorylation, it translocates to the nucleus, where it binds to TEAD and promotes the transcription of genes involved in the proliferation and metastasis of cancer cells $(10,16,17)$. However, Nguyen et al showed that LKB1 inhibits the proliferation of 
cancer cells by directly phosphorylating Yap, independently of either large tumor suppressor (LATS) phosphorylation or AMPK/mTOR signaling [see ref. 10 in the study by Nguyen et al (11)]. In lung cancer cells, LKB1 binds directly to the adenomatous polyposis coli (APC)/glycogen synthase kinase-3 $\beta$ (GSK3 $\beta$ ) destruction complex, inducing the degradation of $\beta$-catenin (14), and thus preventing $\mathrm{Wnt} / \beta$-catenin signaling. Yap was also reported to protect $\beta$-catenin from degradation in the cytoplasm, by recruiting $\beta$-transducin repeat containing E3 ubiquitin protein ligase $(\beta-\mathrm{TrCP})$ ubiquitin ligase away from the Axin/GSK3 $\beta$ destruction complex (18) in cancer cells. However, Imajo et al (19) reported that Yap suppresses Wnt/ $\beta$-catenin signaling by its direct binding to $\beta$-catenin in the cytoplasm, which prevents its nuclear translocation. Therefore, the underlying mechanism of LKB1 in its role as a tumor suppressor in cancer cells is uncertain.

A positive correlation was demonstrated between LKB1 expression levels and prognosis of patients with colorectal (20), liver (21), lung (22) and pancreatic (23) cancer, whereas high LKB1 expression is associated with poor overall and diseasefree survival in patients with breast cancer (24). By contrast, the association between LKB1 and the clinicopathological characters of patients with GC has not been clearly established. In the present study, using immunohistochemical (IHC) staining, we found a negative correlation between LKB1 expression levels and the nuclear staining of Yap and $\beta$-catenin in GC tissues. A clinicopathological analysis revealed that LKB1 correlated negatively with lymph node metastasis, tumor infiltration, and TNM stage in GC and positively with the longer overall survival of GC these patients. We then found that LKB1 suppresses the proliferation and cell cycle progression of GC cells, most likely by inhibiting the nuclear translocation of Yap and $\beta$-catenin.

\section{Patients and methods}

Patients and specimens. Gastric adenocarcinoma (GAC) tissues were obtained from 109 patients with GC who underwent radical tumor resection at the Chinese People's Liberation Army (PLA) General Hospital (Beijing, China) between 2008 and 2014. Normal controls consisted of 54 adjacent non-cancerous (NC) tissues from the same patients. Of these, 54 pairs of GAC and $\mathrm{NC}$ tissues were stored in a refrigerator at $-80^{\circ} \mathrm{C}$ for later use; all $109 \mathrm{GAC}$ and $54 \mathrm{NC}$ tissues were fixed in formalin and embedded in paraffin. The patients ranged in age from 31 to 84 years (median, 57 years). The pathological TNM stages of their tumors were determined based on the revised 7th edition of the American Joint Committee on Cancer staging system. Thus, 25 tumors were classified as stage I, 47 as stage II, 28 as stage III, and 9 as stage IV. The follow-up period was calculated from the date of surgery until December 15, 2014. This study was conducted with the approval of the Ethics Committee of the Chinese PLA General Hospital. All experiments were performed in accordance with internationally recognized guidelines and the Helsinki Declaration.

Reverse transcription-quantitative polymerase chain reaction $(R T-q P C R)$ assays. Total RNA was extracted from GAC tissues and GC cells cultured with TRIzol (Thermo Fisher Scientific, Inc., Waltham, MA, USA) according to the manufacturer's instructions. For mRNA detection, total RNA extracted from cells was reverse transcribed using the PrimeScript $^{\mathrm{TM}}$ RT reagent kit, and qPCR was then performed using SYBR Premix Ex Taq ${ }^{\mathrm{TM}}$ II (both from Takara Bio Inc., Shiga, Japan) and the following primers: LKB1 forward, 5'-GCCGGGACTGACGTGTAGA-3' and reverse, 5'-CCC AAAAGGAAGGGAAAAACC-3'; Yap forward, 5'-GCAACT CCAACCAGCAGCAACA-3' and reverse, 5'-CGCAGCCTC TCСTTCTCCATCTG-3'; $\beta$-catenin forward, 5'-ATGGGT AGGGCAAATCAGTAAGAGGT-3' and reverse, 5'-AAGCAT CGTATCACAGCA GGTTAC-3'. Relative mRNA levels were analyzed using the comparative $\mathrm{Ct}$ method $\left(2^{-\Delta \Delta \mathrm{Ct}}\right)$. All samples were normalized to GAPDH levels and the fold-change between samples was calculated using the comparative $\mathrm{Ct}$ method. All experiments were performed at least 3 times.

Western blotting and antibodies. GAC tissues and GC cells were collected and total protein was extracted with RIPA Lysis and Extraction Buffer (Thermo Fisher Scientific, Inc.). For subcellular fractionation, protein was extracted using NE-PER ${ }^{\mathrm{TM}}$ Nuclear and Cytoplasmic Extraction reagents (Thermo Fisher Scientific, Inc.). Halt ${ }^{\mathrm{TM}}$ Phosphatase Inhibitor Cocktail (Thermo Fisher Scientific, Inc.) was added to preserve protein phosphorylation as required. Proteins were separated by electrophoresis on 6 or $12 \%$ SDS-PAGE gels, transferred to PVDF membranes overnight at $4{ }^{\circ} \mathrm{C}$ and probed with the primary antibodies against LKB1 (1:1,000, AV41743; Sigma-Aldrich, St. Louis, MO, USA), Yap (1:1,000,\#12395), p-Yap (1:1,000, \#13008) (both from Cell Signaling Technology, Danvers, MA, USA), $\beta$-catenin $(1: 4,000$, ab6302), cyclin D1 (1:1,000, ab131475), CTGF (1:5,000, ab6992), Histone H3 (1:5,000, ab1791) (all from Abcam, Cambridge, UK), GAPDH (1:1,000, \#5174; Cell Signaling Technology). GAPDH bands were used as the loading control for cytoplasmic or total proteins, and histone $\mathrm{H} 3$ bands were used as the loading control for nuclear proteins. Proteins were visualized using an ECL kit (Merck Millipore Corp., Bedford, MA, USA) according to the manufacturer's instructions.

Immunohistochemical analysis. Antigen retrieval was performed by incubating the tumor sections at $95^{\circ} \mathrm{C}$ for $30 \mathrm{~min}$. They were then incubated overnight at $4^{\circ} \mathrm{C}$ with a primary antibody against LKB1 (1:500), Yap (1:400,), or $\beta$-catenin (1:500). Sections were washed, and incubated with the appropriate biotinylated secondary antibodies [goat anti-rabbit IgG $(\mathrm{H}+\mathrm{L})$ HRP or goat anti-mouse IgG $(\mathrm{H}+\mathrm{L}) \mathrm{HRP}$, dilution 1:10,000; Abcam] for $30 \mathrm{~min}$, at $20^{\circ} \mathrm{C}$. The reactions were visualized with 3,3'-diaminobenzidine/hydrogen peroxide. The sections were then counterstained with haematoxylin, and washed and mounted with mounting medium. Antigen expression was scored based on the staining intensity ( 0 , no staining; $1^{+}$, weak positive staining; $2^{+}$, moderate positive staining; and $3^{+}$, intense positive staining) and proportion ( 0 , no cells stained; $1^{+},<10 \%$ positive staining; $2^{+}, 10-50 \%$ positive staining; and $3^{+},>50 \%$ positive staining). The scores obtained from the IHC images were then calculated and defined as negative $(\leq 1)$ or positive (2-6), as previously described $(25,26)$. IHC images were examined by two experienced pathologists blinded to clinicopathological data. The final score was evaluated twice.

Culture of GC cells. The human GC cell line AGS was purchased from the Cell Bank of Shanghai, Institutes for Biological 
Sciences, China. The AGS cell line was cultured in RPMI-1640 medium supplemented with $10 \%$ fetal bovine serum (FBS; Gibco, Grand Island, NY, USA) in a humidified incubator at $37^{\circ} \mathrm{C}$ and $5 \% \mathrm{CO}_{2}$.

Construction of expression vectors and cell transfection. The vector for the overexpression of LKB1 was constructed by synthesizing full-length LKB1-DNA and cloning it into a lentiviral vector-GV341 (pGCMV/MCS/Puro) for mammalian expression. The GV341-LKB1 vector and the control GV341 empty vector were produced in HEK293T cells (GenePharma, Shanghai, China) using the second generation packaging vectors, psPAX2 (Addgene plasmid 12260) and pMD2.G (Addgene plasmid 12259). The shRNA sequences targeting LKB1 and Yap were as follows: LKB1, 5'-GCTGAAAG GGATGCTTGAGTATTCAAGAGATACTCAAGCATCCC TTTCAGCTT-3'; Yap, 5'-CCGGGCCACCAAGCTAGA TAAAGAACTCGAGTTCTTTATCTAGCTTGGTGGCTTT TTG-3'. Control shRNAs were constructed using scrambled sequences. Transfections were performed using Lipofectamine 2000 (Invitrogen, Carlsbad, CA, USA).

Human GAC AGS cells were seeded in 6-well plates and incubated for $24 \mathrm{~h}$ prior to transfection, at which time they reached sub-confluence (70-90\%). They were then transfected with GV341-LKB1 or GV341-vector $(8 \mu \mathrm{g})$ and Lipofectamine 2000 $(20 \mu \mathrm{l})$ in Opti-MEM medium (Invitrogen). Five hours posttransfection, the medium was replaced with RPMI-1640 medium containing 10\% FBS. The ability of GV341-LKB1,LKB1-shRNA and Yap-shRNA to regulate the expression of their targets was confirmed by western blotting. Geneticin (Gibco) $(400 \mu \mathrm{g} / \mathrm{ml})$ was added to GV341-LKB1 or GV341 vector-transfected AGS cells to select those stably expressing LKB1 (LKB1 cells) or the empty vector (Vec cells). For the simultaneous silencing of LKB1 or Yap, $10 \mu \mathrm{g}$ of the respective shRNAs and $25 \mu \mathrm{l}$ Lipofectamine 2000 were used. GC cells were harvested for downstream analysis $24-72 \mathrm{~h}$ post-transfection.

In vitro cell proliferation assay. The in vitro proliferation of GC cells was quantitated using flow cytometric analysis to determine the number of cells. GC cells were seeded in 6-well plates, transfected with GV341-LKB1 or GV341-vector, and incubated for $2 \mathrm{~h}$ at $37^{\circ} \mathrm{C}$ for 5 days. The number of cells were determined based on the absorbance at $450 \mathrm{~nm}$, measured using a BD FACSCalibur (BD Biosciences, Franklin Lake, NJ, USA). Cell growth in vitro was also evaluated by clonogenic assays, using a Multiskan spectrum spectrophotometer (Thermo Fisher Scientific, Inc.). LKB1 and Vec cells were seeded in 6-well plates (1,000 cells/well) in triplicate, and then incubated for 10-14 days until visible colonies had formed. The colonies were fixed with methanol, washed with water, stained with crystal violet, and then counted.

Cell cycle assessment. GC cells were seeded in 6-cm cell culture dishes, transfected with GV341-LKB1 or GV341-vector, and harvested by trypsinization $24-72 \mathrm{~h}$ post-transfection. The cells were then fixed with $70 \%$ ethanol overnight at $4^{\circ} \mathrm{C}$, and incubated with RNaseA (R4875; Sigma-Aldrich) $(50 \mu \mathrm{g} / \mathrm{ml})$ for $30 \mathrm{~min}$ and subsequently stained with propidium iodide (PI). Cell cycle distribution was analyzed by flow cytometric analysis using a BD FACSCalibur.
In vivo cell proliferation assay. Equal numbers $\left(0.2 \mathrm{mlx} 1 \times 10^{6}\right)$ of AGS cells stably expressing GV341-LKB1 or the empty vector were injected subcutaneously into the left armpit of 4-week-old immunodeficient BALB/c nude mice (Charles River, Tokyo, Japan). Twenty-four BALB/c nude mice were purchased from Vitalriver Company (Beijing, China), and were sacrificed by high concentrations of $\mathrm{CO}_{2}$. Tumor formation was measured once every 4 days, and tumor volume was calculated by $1 / 2 \mathrm{x}$ length $\mathrm{x}$ width ${ }^{2}$ for 3 weeks. All mouse experiments were approved by the Ethics Committee of the Chinese PLA General Hospital. All experiments involving mice were performed in accordance with internationally recognized guidelines and the Helsinki Declaration.

Statistical analysis. All experiments were performed at least three times. The results of experiments comparing two groups were analyzed using a two-tailed Student's t-test. Pearson's $\chi^{2}$ test was used to assess the various clinicopathological characteristics as a function of LKB1 expression determined by IHC analysis. The correlation between LKB1 and Yap or $\beta$-catenin was determined using Spearman's correlation coefficient test. Cumulative survival curves were drawn using the Kaplan-Meier method. The difference between the curves was analyzed using the log-rank test. A P-value $<0.05$ was considered to indicate a statistically significant difference. The Statistical Package for the Social Sciences version 19.0 (SPSS Inc., Chicago, IL, USA) was used for all statistical analyses.

\section{Results}

LKB1 expression and the protein ratio of $p$-Yap/Yap are low in GAC tissues. To determine the expression of LKB1 and its association with Yap and $\beta$-catenin, we first measured the mRNA and protein levels in GAC tissues and adjacent NC tissues. The relative mRNA levels were measured using RT-qPCR in the 54 pairs of GAC andNC tissues. It wasclearthat LKB1 mRNA expression was lower $(0.33 \pm 0.04$ vs. $1.0 \pm 0.10$, $\mathrm{P}=0.001)$ and $Y a p(1.84 \pm 0.13$ vs. $1.0 \pm 0.11, \mathrm{P}=0.019)$ and $\beta$-catenin ( $1.63 \pm 0.11$ vs. $1.0 \pm 0.09, \mathrm{P}=0.027) \mathrm{mRNA}$ expression levels were higher in GAC tissues compared with NC tissues (Fig. 1A). The LKB1, p-Yap, Yap and $\beta$-catenin protein levels were measured using western blotting, and it was revealed that LKB1 and p-Yap were lower and that Yap and $\beta$-catenin were higher in GAC tissues compared with NC tissues (Fig. 1B). The relative LKB1 protein level in GAC tissues was significantly lower in GAC tissues than in NC tissues ( $0.37 \pm 0.061$ vs. $0.59 \pm 0.108, \mathrm{P}=0.006)$ (Fig. 1C). Further analysis showed that the protein expression ratio of $\mathrm{p}$-Yap/Yap was also lower in GAC tissues compared with NC tissues $(0.179 \pm 0.085$ vs. $0.8 \pm 0.126, P=0.001)$ (Fig. 1D). Taken together, these results demonstrate that the LKB1 expression level and the ratio of $\mathrm{p}$-Yap/Yap were lower in GAC tissues compared with NC tissues.

LKB1 expression in GAC tissues correlates negatively with the nuclear accumulation of Yap and $\beta$-catenin. In order to determine whether aberrant decreased LKB1 in GAC tissues was associated with the expression and location of Yap and $\beta$-catenin, we evaluated them using IHC in 109 GAC tissues and 54 adjacent $\mathrm{NC}$ tissues. LKB1 staining was weak in 

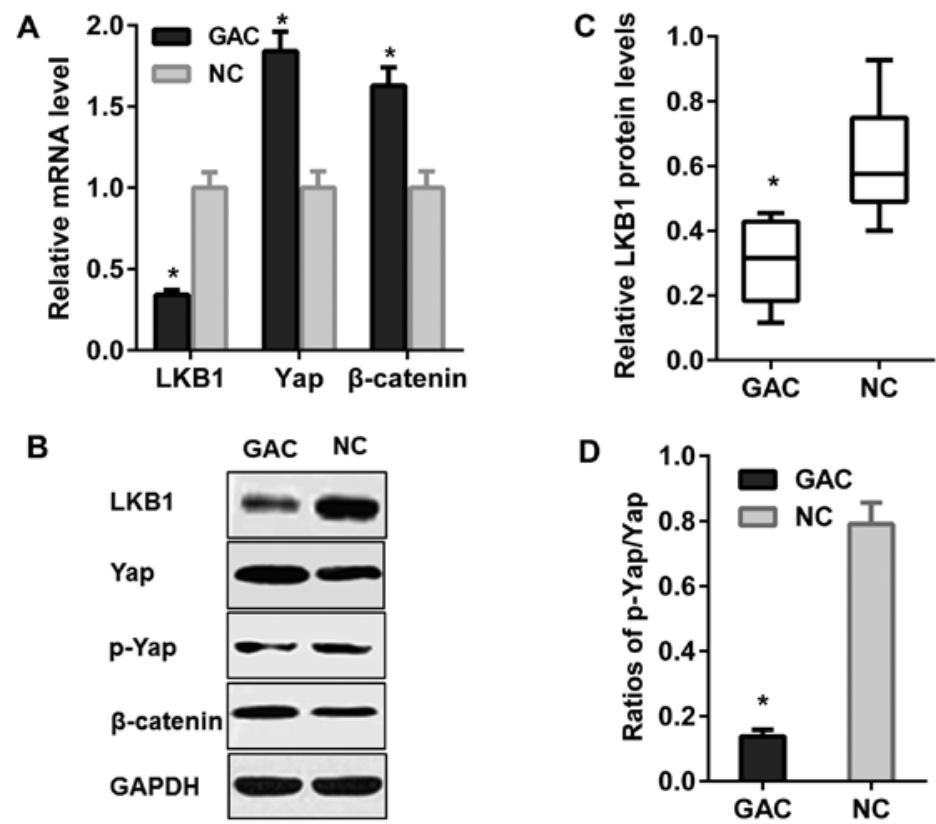

Figure 1. Liver kinase B1 (LKB1) expression and ratio of p-Yes-associated protein (YaP)/Yap is lower in gastric adenocarcinoma (GAC) tissues. (A) The relative mRNA level of $L K B 1$ was lower $(0.33 \pm 0.04$ vs. $1.0 \pm 0.10, P=0.001)$, but $Y a p(1.84 \pm 0.13$ vs. $1.0 \pm 0.11, P=0.019)$ and $\beta$-catenin $(1.63 \pm 0.11$ vs. $1.0 \pm 0.09$, $\mathrm{P}=0.027)$ mRNA levels were higher in GAC tissues compared with non-cancerous (NC) tissues. (B) LKB1 and p-Yap protein expression levels were lower, but Yap and $\beta$-catenin expression were higher in GAC tissues compared with NC tissues. (C) The relative protein expression level of LKB1 in GAC tissues was significantly lower compared with $\mathrm{NC}$ tissues $(0.37 \pm 0.061$ vs. $0.59 \pm 0.108, \mathrm{P}=0.006, \mathrm{n}=54)$. (D) The ratio of pYap/Yap was lower in in GAC tissues compared with $\mathrm{NC}$ tissues $(0.179 \pm 0.085$ vs. $0.8 \pm 0.126, \mathrm{P}=0.001)$. ${ }^{*} \mathrm{P}<0.05$ was considered to indicate a statistically significant difference.

A
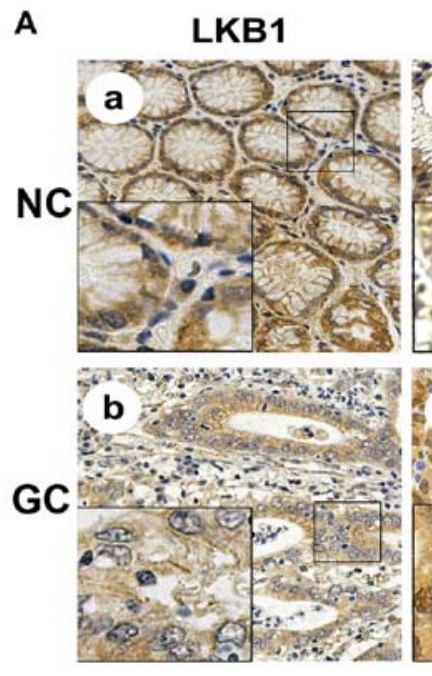

B

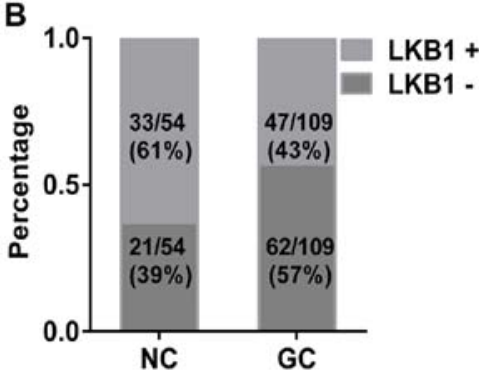

Yap
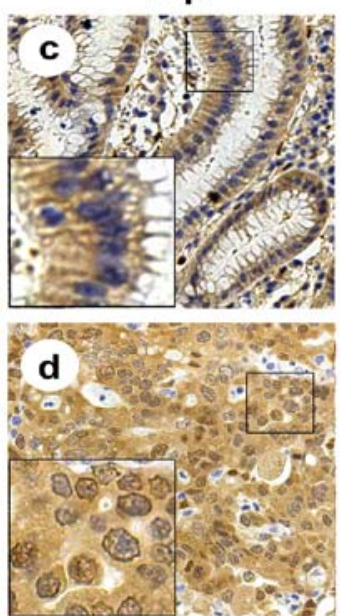

C

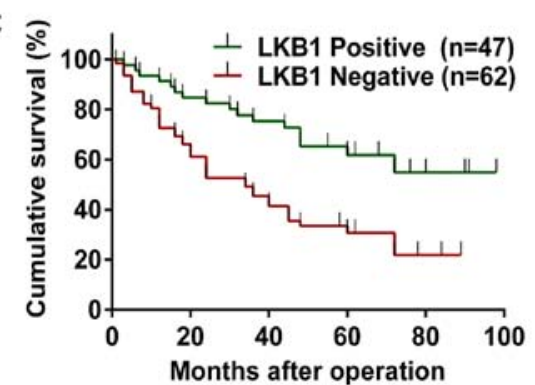

Figure 2. Liver kinase B1 (LKB1) expression correlates negatively with the nuclear accumulation of Yes-associated protein (Yap) and $\beta$-catenin in gastric carcinoma (GAC) tissues and is positively correlated with longer overall survival of gastric cancer (GC) patients. (A) LKB1, Yap and $\beta$-catenin expression was evaluated by IHC staining of GAC tissues and adjacent non-cancerous (NC) tissues. LKB1 staining was (panel a) moderate in NC tissues and (panel b) weak in GAC tissues. (Panel c) Yap was not detected in the nuclei of NC tissues but (panel d) was intensely stained in GAC tissues. (Panel e) $\beta$-catenin was not detected in the nuclei of cells from NC tissues but (panel f) was moderately stained in GAC tissues. (Panels a-f) x100; lower left area, x400. (B) LKB1-positive staining sample was significantly less in GAC than in NC tissues (43 vs. 61\%, P=0.0306). (C) Patients with tumors that positively stained for LKB1 had a longer cumulative overall survival than those with tumors that stained negatively for LKB1 $\left(\chi^{2}=11.778, \mathrm{P}=0.001\right)$. Significance was determined using the log-rank test. A P-value $<0.05$ was considered to indicate statistical significance. 
Table I. Correlation between LKB1 expression and clinicopathological features of GC patients.

\begin{tabular}{|c|c|c|c|c|c|}
\hline \multirow[b]{2}{*}{ Clinicopathological variables } & \multirow[b]{2}{*}{$\mathrm{n}^{\mathrm{a}}$} & \multicolumn{2}{|c|}{ LKB 1} & \multirow[b]{2}{*}{$\chi^{2}$} & \multirow[b]{2}{*}{ P-value } \\
\hline & & Positive & Negative & & \\
\hline All patients & 109 & 47 & 62 & & \\
\hline Age (years) & & & & 3.1320 & 0.0768 \\
\hline$<60$ & 50 & 17 & 33 & & \\
\hline$\geq 60$ & 59 & 30 & 29 & & \\
\hline Gender & & & & 0.0245 & 0.8757 \\
\hline Male & 71 & 31 & 40 & & \\
\hline Female & 38 & 16 & 22 & & \\
\hline Tumor size $(\mathrm{cm})$ & & & & 6.9373 & $0.0084^{c}$ \\
\hline$<4$ & 32 & 20 & 12 & & \\
\hline$\geq 4$ & 77 & 27 & 50 & & \\
\hline Histopathological grading & & & & 0.1069 & 0.7437 \\
\hline Differentiated & 63 & 28 & 35 & & \\
\hline Undifferentiated & 46 & 19 & 27 & & \\
\hline Lymphatic invasion & & & & 0.1470 & 0.7015 \\
\hline 0 & 44 & 18 & 26 & & \\
\hline $1-3$ & 65 & 29 & 36 & & \\
\hline TNM classification & & & & & \\
\hline $\mathrm{T}$ categories & & & & 13.1648 & $0.0043^{\mathrm{c}}$ \\
\hline $\mathrm{T} 1$ & 18 & 12 & 6 & & \\
\hline $\mathrm{T} 2$ & 29 & 17 & 12 & & \\
\hline T3 & 45 & 15 & 30 & & \\
\hline $\mathrm{T} 4$ & 17 & 3 & 14 & & \\
\hline $\mathrm{N}$ categories & & & & 6.3017 & $0.0428^{c}$ \\
\hline No & 29 & 18 & 11 & & \\
\hline $\mathrm{N} 1 / 2$ & 37 & 15 & 22 & & \\
\hline N3 & 43 & 14 & 29 & & \\
\hline TNM stage $(\mathrm{AJCC})^{\mathrm{b}}$ & & & & 8.2511 & $0.0411^{\mathrm{c}}$ \\
\hline I & 25 & 14 & 11 & & \\
\hline II & 47 & 24 & 23 & & \\
\hline III & 28 & 7 & 21 & & \\
\hline IV & 9 & 2 & 7 & & \\
\hline Yap nuclear location & & & & 53.3644 & $0.0000^{\mathrm{c}}$ \\
\hline Positive & 64 & 9 & 55 & $r=-0.6997$ & \\
\hline Negative & 45 & 38 & 7 & & \\
\hline$\beta$-catenin nuclear location & & & & 13.4260 & $0.0002^{\mathrm{c}}$ \\
\hline Positive & 59 & 16 & 43 & $\mathrm{r}=-0.3510$ & \\
\hline Negative & 50 & 31 & 19 & & \\
\hline
\end{tabular}

${ }^{\mathrm{a} N u m b e r s ~ o f ~ c a s e s ~ i n ~ e a c h ~ g r o u p ; ~}{ }^{\mathrm{b}}$ The AJCC Cancer Staging Manual, 7th edition; ' $\mathrm{Statistically} \mathrm{significant}(\mathrm{P}<0.05)$. T, tumor; N, lymph node; M, metastasis; LKB1, liver kinase B1; GC, gastric cancer; Yap, Yes-associated protein.

GAC tissues (43\%) but intensely positive in NC tissues $(61 \%)$ $\left(\chi^{2}=4.678, P=0.0306\right)$ (Fig. $2 \mathrm{~A}$, panels a and b, and Fig. 2B). Nuclear Yap was negative in NC tissues but intensely positive in GAC tissues (Fig. 2A, panels c and d). $\beta$-catenin was also negative in $\mathrm{NC}$ tissues, whereas moderately positive staining was noted in GAC tissues (Fig. 2A, panels e and f). Spearman's correlation coefficient analysis indicated a negative correlation between LKB1 expression and the nuclear staining of both Yap $(\mathrm{r}=-0.6997)$ and $\beta$-catenin $(\mathrm{r}=-0.3510)$ (Table I). Therefore, LKB1 expression was negatively correlated with the nuclear accumulation of Yap and $\beta$-catenin in GAC tissues.

LKB1 expression in GAC is positively correlated with better prognosis. Since the clinicopathological associations between 
Table II. Univariate and multivariate analyses of overall survival of GC patients.

\begin{tabular}{|c|c|c|c|c|}
\hline \multirow[b]{2}{*}{ Variables } & \multirow{2}{*}{$\frac{\text { Univariate }^{\mathrm{a}}}{\mathrm{P} \text {-value }}$} & \multicolumn{3}{|c|}{ Multivariate $^{\mathrm{b}}$} \\
\hline & & HR & $95 \% \mathrm{CI}$ & P-value \\
\hline \multicolumn{5}{|l|}{ Gender } \\
\hline Male vs. female & 0.7750 & 1.230 & $0.857-2.035$ & 0.0740 \\
\hline \multicolumn{5}{|l|}{ Age (years) } \\
\hline$\geq 60$ vs. $<60$ & 0.1330 & 1.453 & $0.793-2.274$ & 0.0628 \\
\hline \multicolumn{5}{|l|}{ Tumor size (cm) } \\
\hline$\geq 4$ vs. $<4$ & $0.0002^{\mathrm{c}}$ & 5.490 & $2.105-14.143$ & $0.0152^{\mathrm{c}}$ \\
\hline \multicolumn{5}{|l|}{ Histopathological grading } \\
\hline Differentiated vs. undifferentiated & 0.8103 & 1.144 & $0.9102-1.572$ & 0.0751 \\
\hline \multicolumn{5}{|l|}{ Tumor infiltration } \\
\hline T3-4 vs. T1-2 & $0.0011^{\mathrm{c}}$ & 1.930 & $1.550-2.584$ & $0.0018^{\mathrm{c}}$ \\
\hline \multicolumn{5}{|l|}{ Lymph node metastasis } \\
\hline N1-3 vs. N0 & $0.0028^{c}$ & 1.562 & $1.460-4.150$ & 0.0320 \\
\hline \multicolumn{5}{|l|}{ LKB1 expression } \\
\hline Positive vs. negative & $0.0053^{\mathrm{c}}$ & 3.527 & $1.491-10.630$ & $0.0077^{\mathrm{c}}$ \\
\hline
\end{tabular}

LKB1 expression and the GAC patients were unclear, we assessed the clinicopathological characteristics and the prognosis of these GAC patients. The clinicopathological characteristics of patients with GC were analyzed using Pearson's $\chi^{2}$ test, which showed a negative association between LKB1 expression level and tumor size $(\mathrm{P}=0.0084)$, tumor infiltration $(\mathrm{P}=0.0043)$, lymph node metastasis $(\mathrm{P}=0.0428)$, and TNM stage $(\mathrm{P}=0.0411)$ (Table $\mathrm{I})$. In cumulative survival curves obtained using Kaplan-Meier analysis, postoperative overall survival was longer in patients with LKB1-positive tumors (median, 55 months) than in those with LKB1-negative tumors (median, 34 months; $\chi^{2}=11.778, P=0.001$ ) (Fig. 2C). In a univariate analysis using the Cox proportional hazard regression model, LKB1 expression $(\mathrm{P}=0.0053)$, tumor size $(\mathrm{P}=0.0002)$, tumor infiltration $(\mathrm{P}=0.0011)$, and lymph node metastasis $(\mathrm{P}=0.0028)$ were significantly associated with cause-specific survival (Table II). In a multivariate analysis using forward and backward stepwise Cox regression, LKB1 expression was an independent prognostic factor $(\mathrm{P}=0.0077$; hazard ratio, 3.527; 95\% confidence interval, 1.491-10.630).

LKB1 causes the increase in p-Yap expression and the suppression of GC cell proliferation in vitro. Although LKB1 has been reported to suppress the proliferation and survival of many types of cancer cells $(11,14,23)$, its effects on GC cells required further research. Therefore, AGS GC cells were transfected with a full-length LKB1 vector (LKB1 cells) or an empty vector (Vec cells). Western blotting revealed that LKB1 and $\mathrm{p}$-Yap expression levels were notably increased in the LKB1 cells compared with Vec cells, but Yap expression barely changed (Fig. 3A). Moreover, the target protein of Yap, CTGF, and the target protein of $\beta$-catenin, cyclin D1, which promote cell proliferation and cell cycle progression, were decreased in LKB1 cells compared with Vec cells (Fig. 3A). Flow cytometric analysis carried out at $48 \mathrm{~h}$ post-transfection indicated a decrease in the number of cells in LKB1 cells compared with Vec cells (Fig. 3B). A cell cycle analysis showed an increase in the number of cells in the G0G1 phase and a decrease in the numbers of cells in $\mathrm{S}$ and $\mathrm{G} 2 / \mathrm{M}$ phases in LKB1 vs. Vec cells $(53.01 \pm 4.7$ vs. $36.41 \pm 3.2 \%, \mathrm{P}=0.0022)$ (Fig. $3 \mathrm{C}$ and $\mathrm{D}$ ). The clonogenic assays aimed at evaluating the impact of LKB1 on cell growth in vitro were measured using a Multiskan spectrum spectrophotometer at $570 \mathrm{~nm}$, and revealed fewer LKB1 compared with Vec cell colonies $(1.98 \pm 0.64$ vs. $0.85 \pm 0.20$, $\mathrm{P}=0.03$ ) (Fig. 3E).These results suggest that LKB1 induced the increase of $\mathrm{p}$-Yap and suppressed proliferation of GC cells in vitro.

LKB1 suppresses the proliferation of GC cells in vivo. To evaluate the impact of LKB1 on cell growth in vivo, equal numbers of LKB1 or Vec cells were injected into the subcutaneous tissues of $\mathrm{BALB} / \mathrm{c}$ nude mice, and the volume of the resulting subcutaneous tumors was measured every 4 days for 3 weeks. Tumors derived from LKB1 cells were found to grow more slowly and grew to a smaller size compared with those derived from Vec cells (Fig. 3F and G), suggesting that LKB1 inhibits the proliferation of GC cells in vivo.

LKB1 inhibits the nuclear translocation of Yap in GC cells. To determine whether the location of Yap was related to the regulation of LKB1 in GC cells, the subcellular expression levels of $\mathrm{p}$-Yap and Yap were assessed using western blotting in LKB1 cells and Vec cells. The cytoplasmic p-Yap and Yap expression levels were increased in LKB1 cells, but 
A

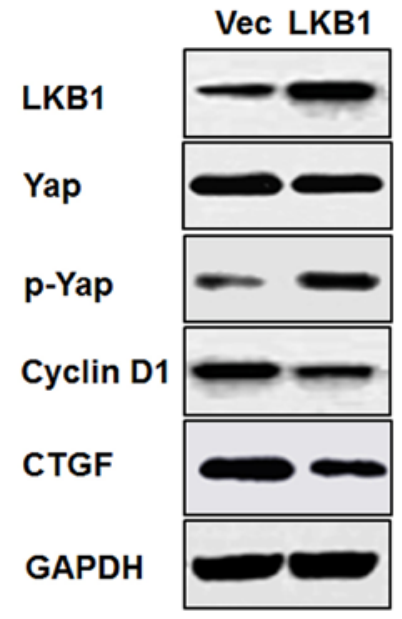

B

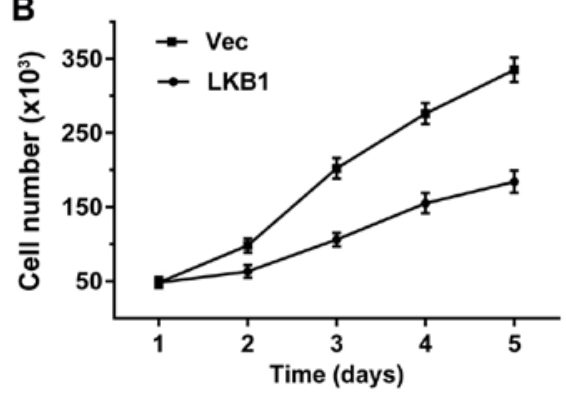

C
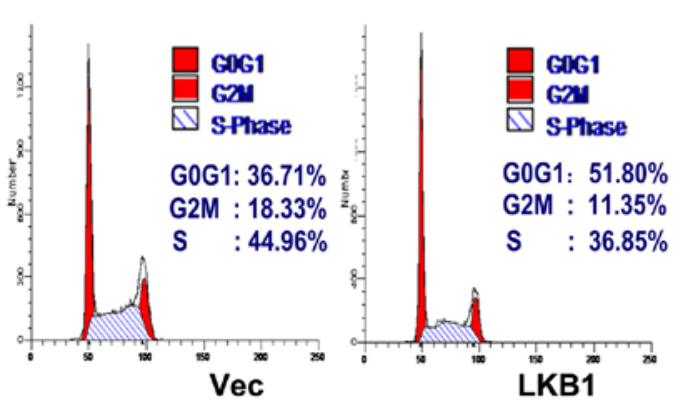

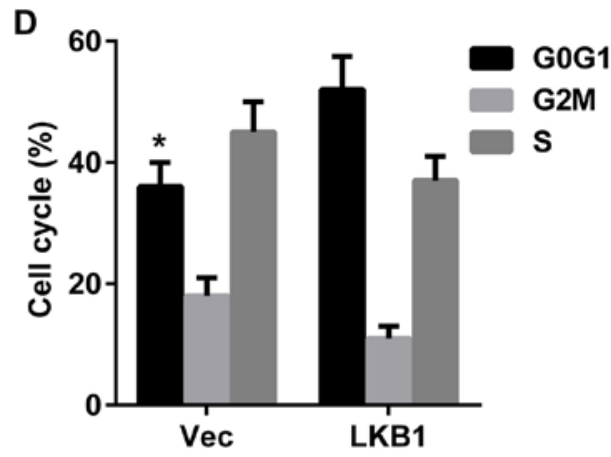

E

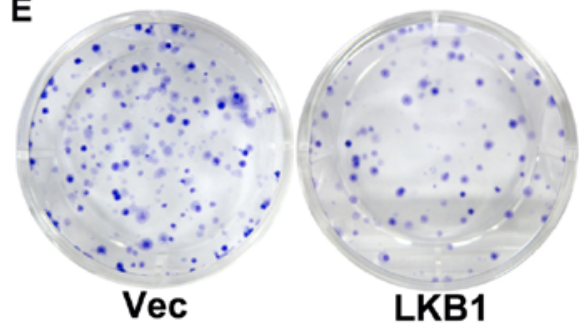

$\mathbf{F}$

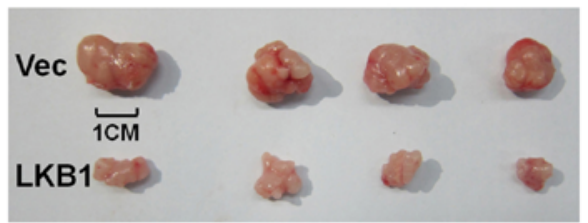

G

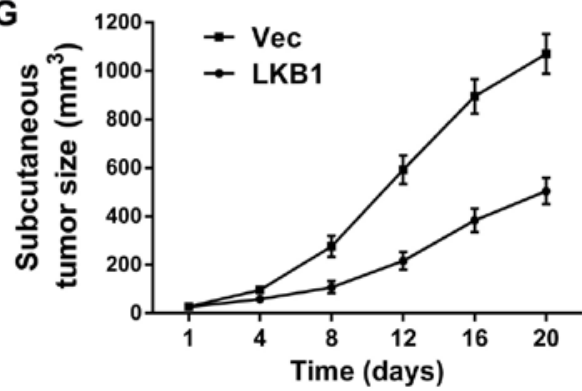

Figure 3. Liver kinase B1 (LKB1) induces the increase of p-Yap expression and suppresses gastric cancer (GC) cell proliferation in vitro. (A) The expression levels of LKB1 and p-Yes-associated protein (Yap) were increased, and cyclin D1 and CTGF were decreased in cells transfected with GV341-LKB1 (LKB1 cells) compared to those transfected with empty vector (Vec cells), but Yap was barely changed. (B) The number of AGS GC cells was lower in cells transfected with LKB1 than the vector-transfected cells, as determined using flow cytometric analysis. (C and D) The proportion of cells in the G0G1 phase was higher (53.01 \pm 4.7 vs. $36.41 \pm 3.2 \%, P=0.0022)$ in LKB1 cells than in Vec cells. (E) Cell colonies formed by LKB1 were fewer than in Vec cells ( $1.98 \pm 0.64$ vs. $0.85 \pm 0.20$, $\mathrm{P}=0.03$ ), as measured by a Multiskan spectrum spectrophotometer at $570 \mathrm{~nm}$. (F and G) Subcutaneous tumors derived from LKB1 cells were (F) smaller and (G) grew more slowly than those derived from Vec cells $(n=8, P=0.01) .{ }^{*} \mathrm{P}<0.05$ was considered to indicate a statistically significant difference.

nuclear Yap expression was decreased compared with the Vec cells (Fig. 4A). In addition no p-Yap was detected in the nucleus of GC cells (Fig. 4A). Further analysis revealed that the cytoplasmic Yap ratio of LKB1 cells to Vec cells was higher than the nuclear Yap ratio $(1.27 \pm 0.26$ vs. $0.43 \pm 0.18$, $\mathrm{P}=0.017$ ) (Fig. 4B). However, the relative mRNA level of Yap was barely altered by LKB1 overexpression (Fig. 4D). The results suggest that LKB1 phosphorylates Yap and inhibits its nuclear translocation, which is consistent with the results of previous studies $(10,16)$.

LKB1 induces the cytoplasmic accumulation of $\beta$-catenin via Yap in GC cells. To better understand the role of LKB1 in the regulation of Yap and $\beta$-catenin, LKB1 and Yap were individually silenced using shRNAs in LKB1-overexpressing cells, after which the levels of Yap and $\beta$-catenin in the cytoplasm and nucleus were determined. The levels of Yap and $\beta$-catenin in the cytoplasm were higher in LKB1-overexpressing GC cells than in Vec cells, whereas transfection with LKB1-shRNA or Yap-shRNA made these levels decrease (Fig. 4C). In the nucleus, however, Yap and $\beta$-catenin levels were lower in LKB1 than in Vec cells, an effect that was reversed by LKB1-shRNA transfection. In LKB1-overexpressing GC cells, the transfection of Yap-shRNA led to a further decrease of nuclear Yap and an increase in nuclear $\beta$-catenin (Fig. 4C). Taken together, these results suggest that LKB1 induces the accumulation of cytoplasmic $\beta$-catenin in GC cells, which, at least partially, is due to the cytoplasmic accumulation of Yap.

The role of LKB1 and Yap in the regulation of $\beta$-catenin was further examined by measuring the relative mRNA 


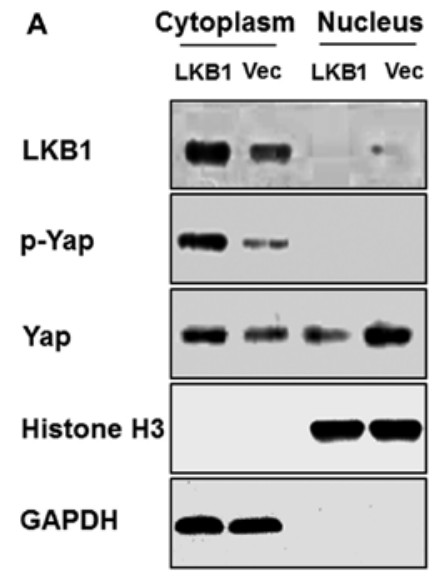

B

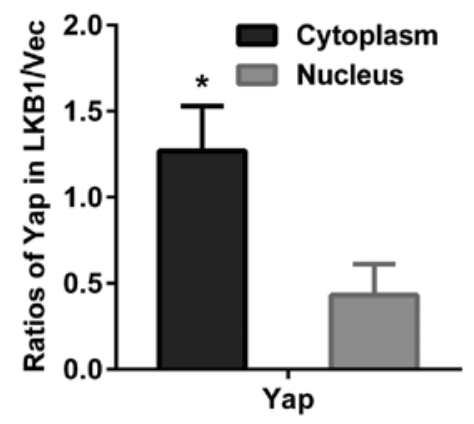

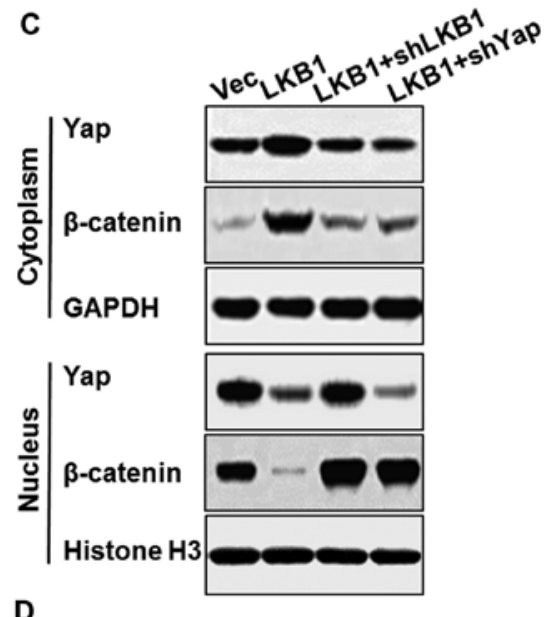

D

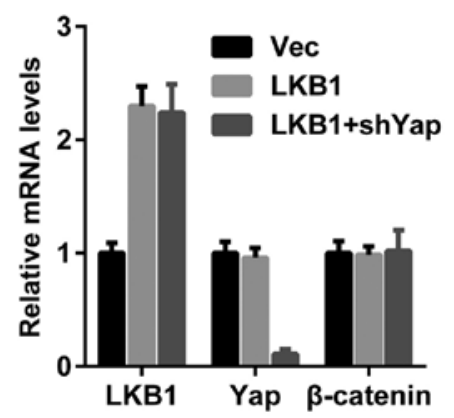

Figure 4. Liver kinase B1 (LKB1) leads to the cytoplasmic translocation of Yes-associated protein (Yap) and $\beta$-catenin in gastric cancer (GC) cells. Cytoplasmic and nuclear proteins were extracted from LKB1 cells and Vec cells. (A) The levels of p-Yap and Yap in the cytoplasm were higher whereas the nuclear Yap level was lower in LKB1 than in Vec cells, but p-Yap was not detected in their nuclei. (B) The Yap ratio of LKB1 to Vec cell was higher in the cytoplasm than in the nucleus $(1.27 \pm 0.26$ vs. $0.43 \pm 0.18, \mathrm{P}=0.017)$. (C) Cytoplasmic Yap and $\beta$-catenin expression was higher in LKB1 cells but decreased in LKB1 cells transfected with LKB1-shRNA or Yap-shRNA. Nuclear Yap and $\beta$-catenin expression levels were lower in LKB1 cells than in Vec cells, which was reversed by LKB1-shRNA transfection. Nuclear $\beta$-catenin expression was increased in Yap shRNA-transfected LKB1 cells. (D) Relative mRNA levels of LKB1, Yap and $\beta$-catenin were measured using RT-qPCR. The relative mRNA level of LKB1 was increased by full-length LKB1 transfection, and Yap mRNA was decreased by Yap-shRNA transfection. However, Yap and $\beta$-catenin mRNA levels were almost unchanged in LKB1 cells compared with Vec cells. $\beta$-catenin mRNA levels were almost unchanged in Yap shRNA-transfected LKB1 vs. Vec cells. "P<0.05 was considered to indicate a statistically significant difference.

levels of LKB1, Yap and $\beta$-catenin in LKB1 cells and Vec cells. Silencing of both LKB1 or Yap had almost no effect on $\beta$-catenin mRNA levels (Fig. 4D). Based on these observations, we concluded that LKB1 expression promotes the accumulation of cytoplasmic $\beta$-catenin in GC cells by inhibiting the nuclear translocation of Yap, rather than by suppressing the transcription of $\beta$-catenin.

\section{Discussion}

LKB1 acts as a critical regulator in the AMPK/mTOR, Wnt/ $\beta$-catenin, and Hippo signaling pathways in various types of cancers $(10,11,14)$. However, the underlying mechanisms linking LKB1 to its diverse functions in GC remain unclear, and they are further complicated by the cross-talk between different signaling pathways. Previous studies have reported that sporadic LKB1 mutations are rare in metastatic (3.4\%) (6) and advanced (2.1\%) (7) GC, and thus wild-type LKB1 plays an important function in the regulation of associated signaling pathways.

In the present study, we found that the LKB1 expression level and protein ratio of p-Yap/Yap was lower in GAC tissues compared with adjacent NC tissues. Further IHC analysis revealed significantly lower LKB1 staining in GAC tissues than in NC tissues and a negative correlation between LKB1 and the nuclear staining of Yap and $\beta$-catenin. The elevated expression and nuclear accumulation of Yap has previously been shown to be associated with promoted GC progression (27). The nuclear translocation of $\beta$-catenin has been implicated in gastric carcinogenesis in murine adult gastric epithelium (28), and in the invasiveness of GC (29). In the present study, we found that LKB1 expression was negatively associated with tumor size, tumor infiltration, lymph node metastasis, and TNM stage, and positively associated with longer overall survival of GC patients. Taken together, these results suggest that LKB1 expression is decreased in GAC tissues and is negatively associated with the nuclear accumulation of Yap and $\beta$-catenin, which is related to poor prognosis of GC patients.

Mohseni et al (10) reported that LKB1 inhibits Yap activation via the canonical Hippo-LATS-Yap signaling axis, whereas Nguyen et al (11) found that LKB1 phosphorylates Yap independently of LATS phosphorylation. In order to determine whether LKB1 expression affects the expression and location of Yap, in the present study, we transfected a full-length LKB1 into the AGS GC cells and observed an increase in p-Yap expression whereas Yap expression remained almost unchanged. The potential regulation of Yap by LKB1 in GC cells was assessed by examining the expression and subcellular location of Yap. 
We found that LKB1 overexpression induced an increase in cytoplasmic p-Yap and the protein ratio of p-Yap/Yap, leading to a decrease in nuclear unphosphorylated Yap. A decrease in the expression of CTGF (27), the target gene of Yap has been noted, but the Yap mRNA level was not markedly altered between LKB1 and vector-transfected cells. Therefore, we believe that LKB1 induces the nuclear translocation of Yap.

Moreover, LKB1 overexpression led to a cell cycle arrest in $\mathrm{G} 1$, a decrease in the cell cycle protein, cyclin D1, which is an important target gene of $\beta$-catenin (30). Previous studies reported that the aberrant nuclear location of Yap (31) and $\beta$-catenin (30), effectors of Hippo and Wnt/ $\beta$-catenin signaling pathways, are related to proliferation and cell cycle progression of cancer cells. Consistent with previous studies, LKB1-overexpressing GC cells demonstrated a decreased proliferation in vitro and in vivo. Taken together, LKB1 inhibits the proliferation of GC cells via suppressing the nuclear translocation of Yap and associated with the nuclear accumulation of $\beta$-catenin.

LKB1 has been shown to induce the degradation of $\beta$-catenin $(32,33)$ by binding to and activating the APC/GSK3 $\beta$ destruction complex, resulting in $\mathrm{Wnt} / \beta$-catenin signaling inhibition and tumor suppression. Yap has been shown to preserve cytoplasmic $\beta$-catenin by recruiting $\beta$-TrCP ubiquitin ligase away from the Axin/GSK3 $\beta$ destruction complex, leading to the inactivation of the latter in cancer cells (18). Yap also binds $\beta$-catenin directly in the cytoplasm, which prevents its nuclear translocation and thereby inhibits the expression of Wnt/ $\beta$-catenin target genes (19). In the present study, we assessed the expression and subcellular location of Yap and $\beta$-catenin in LKB1 cells and in Yap shRNA-transfected LKB1 cells, and found that LKB1 overexpression induced the accumulation of Yap and $\beta$-catenin in the cytoplasm, thus preventing their nuclear localization. Interestingly, Yap silencing in LKB1-transfected cells led to a decrease of $\beta$-catenin in the cytoplasm but an increase of the protein in the nucleus, which suggested that LKB1 and cytoplasmic Yap inhibit the nuclear accumulation of $\beta$-catenin in GC cells, as previously reported (18). By measuring the relative mRNA levels, we were able to demonstrate that the transcription of $\beta$-catenin was almost unchanged in LKB1 cells and in Yap-silenced LKB1 cells. Taken together, our results suggest that LKB1 phosphorylates Yap and inhibits its nuclear accumulation via the Hippo signaling pathway and thereby induces nuclear translocation of $\beta$-catenin in GC cells.

Cross-talk between Yap and $\beta$-catenin in cancer cells has previously been demonstrated in several studies. Rosenbluh et al reported that the binding of Yap to $\beta$-catenin results in a transcriptional complex that promotes tumor progression in $\beta$-catenin-driven cancer cells, including AGS cells (34). Konsavage et al have reported that $\beta$-catenin drives Yap transcription in colorectal cancer cells (35). Yap is also a target of SOX 2 and binds $\beta$-catenin, thus indirectly dampening Wnt signals that regulate osteoblastic and adipocytic stem cell lineages (36). Given the complexity of the cross-talk between Yap and $\beta$-catenin, we did not further examine the mechanism underlying the regulation of $\beta$-catenin by Yap in GC cells.

In conclusion, the present study revealed that LKB1 expression is decreased in GAC tissues and is correlated negatively with the nuclear accumulation of Yap and $\beta$-catenin. IHC analysis demonstrated a negative association between LKB1 expression and tumor size, infiltration, lymph node metastasis and TNM stage. Higher levels of LKB1 were also associated with the longer overall survival of GC patients. Further investigation revealed that LKB1 inhibited the nuclear translocation of Yap and $\beta$-catenin, suggesting a mechanism which accounts for its suppression of the proliferation of GC cells observed in vitro and in vivo.

\section{Acknowledgements}

The study was supported by a grant from the Project supported by the National High Technology Research and Development Program of China (no. 2012AA02A504), a grant from the Special Scientific Research Foundation of Health Sector from the National Health and Family Planning Commission of China (no. 201302016), a grant from the PLA Medical Technology Key Project of Scientific Research in the 12th research projects in 12th Five-Year-Plan (no. BWS12J049), and a grant from the People's Liberation Army Medical Technology Project for Fostering Youth (no. 13QNP185),

\section{References}

1. Hemminki A, Markie D, Tomlinson I, Avizienyte E, Roth S, Loukola A, Bignell G, Warren W, Aminoff M, Höglund P, et al: A serine/threonine kinase gene defective in Peutz-Jeghers syndrome. Nature 391: 184-187, 1998.

2. Gill RK, Yang SH, Meerzaman D, Mechanic LE, Bowman ED, Jeon HS, Roy Chowdhuri S, Shakoori A, Dracheva T, Hong KM, et al: Frequent homozygous deletion of the LKB1/STK11 gene in non-small cell lung cancer. Oncogene 30: 3784-3791, 2011.

3. Wingo SN, Gallardo TD, Akbay EA, Liang MC, Contreras CM, Boren T, Shimamura T, Miller DS, Sharpless NE, Bardeesy N, et al: Somatic LKB1 mutations promote cervical cancer progression. PLoS One 4: e5137, 2009.

4. Kim CJ, Cho YG, Park JY, Kim TY, Lee JH, Kim HS, Lee JW, Song YH, Nam SW, Lee SH, et al: Genetic analysis of the LKB1/STK11 gene in hepatocellular carcinomas. Eur J Cancer 40: 136-141, 2004.

5. Birnbaum DJ, Adélaïde J, Mamessier E, Finetti P, Lagarde A, Monges G, Viret F, Gonçalvès A, Turrini O, Delpero JR, et al: Genome profiling of pancreatic adenocarcinoma. Genes Chromosomes Cancer 50: 456-465, 2011.

6. Kim S, Lee J, Hong ME, Do IG, Kang SY, Ha SY, Kim ST, Park SH, Kang WK, Choi MG, et al: High-throughput sequencing and copy number variation detection using formalin fixed embedded tissue in metastatic gastric cancer. PLoS One 9: e111693, 2014.

7. Lee J, van Hummelen P, Go C, Palescandolo E, Jang J, Park HY, Kang SY, Park JO, Kang WK, MacConaill L and Kim KM: High-throughput mutation profiling identifies frequent somatic mutations in advanced gastric adenocarcinoma. PLoS One 7: e38892, 2012.

8. Fassan M, Simbolo M, Bria E, Mafficini A, Pilotto S, Capelli P, Bencivenga M, Pecori S, Luchini C, Neves D, et al: High-throughput mutation profiling identifies novel molecular dysregulation in high-grade intraepithelial neoplasia and early gastric cancers. Gastric cancer 17: 442-449, 2014.

9. Martin-Belmonte F and Perez-Moreno M: Epithelial cell polarity, stem cells and cancer. Nat Rev Cancer 12: 23-38, 2012.

10. Mohseni M, Sun J, Lau A, Curtis S, Goldsmith J, Fox VL, Wei C, Frazier M, Samson O, Wong KK, et al: A genetic screen identifies an LKB1-MARK signalling axis controlling the Hippo-YAP pathway. Nat Cell Biol 16: 108-117, 2014.

11. Nguyen HB, Babcock JT, Wells CD and Quilliam LA: LKB1 tumor suppressor regulates AMP kinase/mTOR-independent cell growth and proliferation via the phosphorylation of Yap. Oncogene 32: 4100-4109, 2013.

12. Patel K, Foretz M, Marion A, Campbell DG, Gourlay R, Boudaba N, Tournier E, Titchenell P, Peggie M, Deak M, et al: The LKB1-salt-inducible kinase pathway functions as a key gluconeogenic suppressor in the liver. Nat Commun 5: 4535, 2014. 
13. Lin YY, Kiihl S, Suhail Y, Liu SY, Chou YH, Kuang Z, Lu JY, Khor CN, Lin CL, Bader JS, et al: Functional dissection of lysine deacetylases reveals that HDAC1 and p300 regulate AMPK. Nature 482: 251-255, 2012.

14. Jian SF, Hsiao CC, Chen SY, Weng CC, Kuo TL, Wu DC, Hung WC and Cheng KH: Utilization of liquid chromatography mass spectrometry analyses to identify LKB1-APC interaction in modulating Wnt $/ \beta$-catenin pathway of lung cancer cells. Mol Cancer Res 12: 622-635, 2014.

15. Jacob LS, Wu X, Dodge ME, Fan CW, Kulak O, Chen B, Tang W, Wang B, Amatruda JF and Lum L: Genome-wide RNAi screen reveals disease-associated genes that are common to Hedgehog and Wnt signaling. Sci Signal 4: ra4, 2011.

16. Gao Y, Zhang W, Han X, Li F, Wang X, Wang R, Fang Z, Tong X, Yao S, Li F, et al: YAP inhibits squamous transdifferentiation of Lkb1-deficient lung adenocarcinoma through ZEB2-dependent DNp63 repression. Nat Commun 5: 4629, 2014.

17. Hsu YL, Hung JY, Chou SH, Huang MS, Tsai MJ, Lin YS, Chiang SY, Ho YW, Wu CY and Kuo PL: Angiomotin decreases lung cancer progression by sequestering oncogenic YAP/TAZ and decreasing Cyr61 expression. Oncogene 34: 4056-4068, 2015.

18. Azzolin L, Panciera T, Soligo S, Enzo E, Bicciato S, Dupont S, Bresolin S, Frasson C, Basso G, Guzzardo V, et al: YAP/TAZ incorporation in the $\beta$-catenin destruction complex orchestrates the Wnt response. Cell 158: 157-170, 2014.

19. Imajo M, Miyatake K, Iimura A, Miyamoto A and Nishida E: A molecular mechanism that links Hippo signalling to the inhibition of Wnt/ $\beta$-catenin signalling. EMBO J 31: 1109-1122, 2012

20. Lee SJ, Kang BW, Chae YS, Kim HJ, Park SY, Park JS, Choi GS, Jeon HS, Lee WK and Kim JG: Genetic variations in STK11, PRKAA1, and TSC1 associated with prognosis for patients with colorectal cancer. Ann Surg Oncol 21 (Suppl 4): S634-S639, 2014.

21. Frau M, Feo F and Pascale RM: Pleiotropic effects of methionine adenosyltransferases deregulation as determinants of liver cancer progression and prognosis. J Hepatol 59: 830-841, 2013.

22. Tsai LH, Chen PM, Cheng YW, Chen CY, Sheu GT, Wu TC and Lee H: LKB1 loss by alteration of the NKX2-1/p53 pathway promotes tumor malignancy and predicts poor survival and relapse in lung adenocarcinomas. Oncogene 33: 3851-3860, 2014

23. Morton JP, Jamieson NB, Karim SA, Athineos D, Ridgway RA, Nixon C, McKay CJ, Carter R, Brunton VG, Frame MC, et al: LKB1 haploinsufficiency cooperates with Kras to promote pancreatic cancer through suppression of p21-dependent growth arrest. Gastroenterology 139: 586-597, 597.e581-586, 2010.

24. Bouchekioua-Bouzaghou K, Poulard C, Rambaud J, Lavergne E, Hussein N, Billaud M, Bachelot T, Chabaud S, Mader S, Dayan $\mathrm{G}$, et al: LKB1 when associated with methylatedER $\alpha$ is a marker of bad prognosis in breast cancer. Int J Cancer 135 . 1307-1318, 2014
25. Xi HQ, Wu XS, Wei B and Chen L: Aberrant expression of EphA3 in gastric carcinoma: correlation with tumor angiogenesis and survival. J Gastroenterol 47: 785-794, 2012.

26. Wood LD, Calhoun ES, Silliman N, Ptak J, Szabo S, Powell SM, Riggins GJ, Wang TL, Yan H, Gazdar A, et al: Somatic mutations of GUCY2F, EPHA3, and NTRK3 in human cancers. Hum Mutat 27: 1060-1061, 2006.

27. Jiao S, Wang H, Shi Z, Dong A, Zhang W, Song X, He F, Wang Y, Zhang Z, Wang W, et al: A peptide mimicking VGLL4 function acts as a YAP antagonist therapy against gastric cancer. Cancer Cell 25: 166-180, 2014.

28. Radulescu S, Ridgway RA, Cordero J, Athineos D, Salgueiro P, Poulsom R, Neumann J, Jung A, Patel S, Woodgett J, et al: Acute WNT signalling activation perturbs differentiation within the adult stomach and rapidly leads to tumour formation. Oncogene 32: 2048-2057, 2013.

29. Aihara R, Mochiki E, Nakabayashi T, Akazawa K, Asao T and Kuwano H: Clinical significance of mucin phenotype, beta-catenin and matrix metalloproteinase 7 in early undifferentiated gastric carcinoma. Br J Surg 92: 454-462, 2005

30. Zhang N, Wei P, Gong A, Chiu WT, Lee HT, Colman H, Huang H, Xue J, Liu M, Wang Y, et al: FoxM1 promotes $\beta$-catenin nuclear localization and controls Wnt target-gene expression and glioma tumorigenesis. Cancer Cell 20: 427-442, 2011.

31. Ehsanian R, Brown M, Lu H, Yang XP, Pattatheyil A, Yan B, Duggal P, Chuang R, Doondeea J, Feller S, et al: YAP dysregulation by phosphorylation or $\Delta \mathrm{Np} 63$-mediated gene repression promotes proliferation, survival and migration in head and neck cancer subsets. Oncogene 29: 6160-6171, 2010.

32. Ossipova O, Bardeesy N, DePinho RA and Green JB: LKB1 (XEEK1) regulates Wnt signalling in vertebrate development. Nat Cell Biol 5: 889-894, 2003.

33. Yan D, Avtanski D, Saxena NK and Sharma D: Leptin-induced epithelial-mesenchymal transition in breast cancer cells requires $\beta$-catenin activation via Akt/GSK3- and MTA1/Wnt1 proteindependent pathways. J Biol Chem 287: 8598-8612, 2012.

34. Rosenbluh J, Nijhawan D, Cox AG, Li X, Neal JT, Schafer EJ, Zack TI, Wang X, Tsherniak A, Schinzel AC, et al: $\beta$-Catenindriven cancers require a YAP1 transcriptional complex for survival and tumorigenesis. Cell 151: 1457-1473, 2012.

35. Konsavage WM Jr, Kyler SL, Rennoll SA, Jin G and Yochum GS: Wnt $/ \beta$-catenin signaling regulates Yes-associated protein (YAP) gene expression in colorectal carcinoma cells. J Biol Chem 287: 11730-11739, 2012.

36. Seo E, Basu-Roy U, Gunaratne PH, Coarfa C, Lim DS, Basilico C and Mansukhani A: SOX2 regulates YAP1 to maintain stemness and determine cell fate in the osteo-adipo lineage. Cell Rep 3: 2075-2087, 2013 